\title{
iBrain: a simulation and visualization tool for activation of brain areas on a realistic 3D brain image Tohru Suzuki1 ${ }^{1}$ Norio Fujimaki² and Kazuhisa Ichikawa*1
}

Address: ${ }^{1}$ Department of Brain and Bioinformation Science, Kanazawa Institute of Technology, Hakusan, Ishikawa, Japan and ${ }^{2}$ Biological ICT Group, Kobe Advanced ICT Research Center, National Institute of Information and Communications Technology, Kobe, Hyougo, Japan

Email: Kazuhisa Ichikawa* - ichikawa@ his.kanazawa-it.ac.jp

* Corresponding author

from Sixteenth Annual Computational Neuroscience Meeting: CNS*2007

Toronto, Canada. 7-12 July 2007

Published: 6 July 2007

BMC Neuroscience 2007, 8(Suppl 2):PI3 doi:I0.I |86/I47|-2202-8-S2-PI3

() 2007 Suzuki et al; licensee BioMed Central Ltd.

\section{Introduction}

Many computer models have been developed to simulate a neuron, neural networks, and activation of brain areas aimed at the elucidation of mechanisms of brain functions. In this track there is one clear direction of modeling from a single cell to the whole brain [1]. We developed a simulation and visualization tool, "iBrain", by which we could construct, simulate and visualize a model of the transition of brain activation on a realistic brain anatomical atlas.

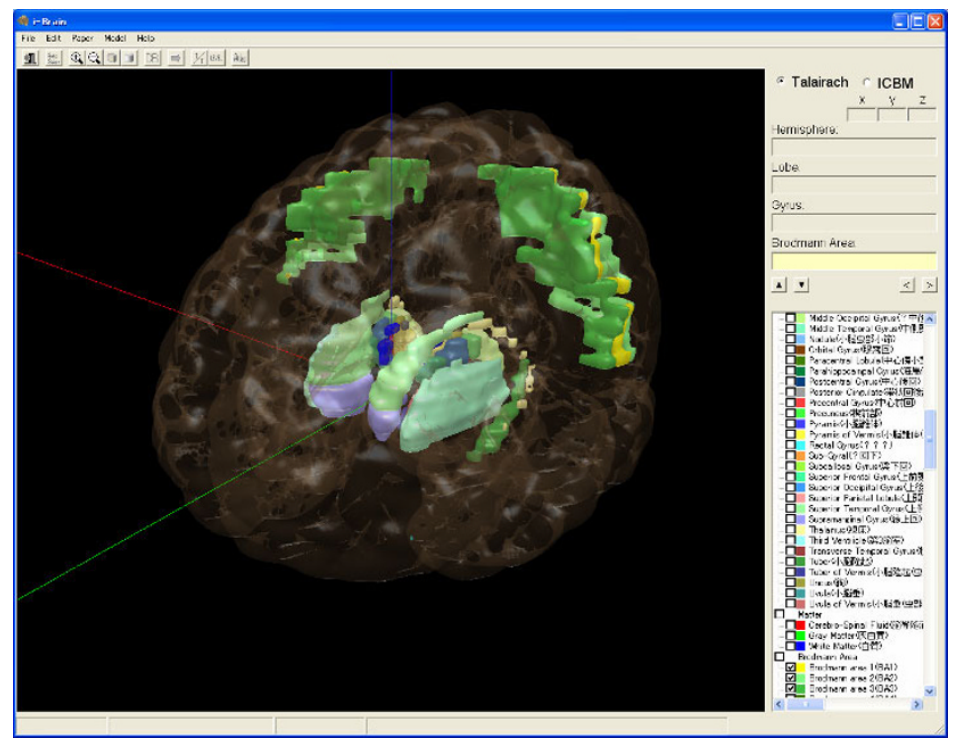

Figure I

An example of Brodmann area display in "iBrain". 


\section{Methods}

The modeling and simulation parts were constructed by modifying the software tool for a biological cell, "A-Cell". Users can construct a Brodmann area-level model through A-Cell like GUI. The simulation algorithm is the same as that in A-Cell. In the visualization part, an anatomical atlas of human brain was constructed from the data of "Talairach Daemon Client" superimposing them on the human brain MRI volume of "ICBM template" from LONI. This allows users to see the shape and position of various anatomical regions of the brain from $\mathrm{mm}$ to hemisphere resolution in the realistic 3D brain (Fig. 1). The activation patterns calculated in the simulation are visualized on this brain image.

\section{Results}

To test the simulator, we tried to reproduce the activation patterns of a human's word processing which were measured by MEG (magneto-encephalogram). The reproduced patterns were roughly matched to the patterns from the experiment and we could see them visually on the iBrain.

\section{Conclusion}

Simulation and visualization of spatio-temporal activation of brain areas on a realistic $3 \mathrm{D}$ brain image can be realized by iBrain. We believe this software can help us to understand the brain function at macroscopic level.

\section{References}

I. Markram H: The blue brain project. Nat Rev Neurosci 2006, 7:153-160.
Publish with Biomed Central and every scientist can read your work free of charge

"BioMed Central will be the most significant development for disseminating the results of biomedical research in our lifetime. " Sir Paul Nurse, Cancer Research UK

Your research papers will be:

- available free of charge to the entire biomedical community

- peer reviewed and published immediately upon acceptance

- cited in PubMed and archived on PubMed Central

- yours - you keep the copyright

Submit your manuscript here:

http://www.biomedcentral.com/info/publishing_adv.asp 